\title{
Effect of Axial Magnetic Field on the Microstructure and Mechanical Properties of CrN Films Deposited by Arc Ion Plating
}

\author{
Yan-Hui Zhao ${ }^{1,2} \cdot$ Li Xu $^{1}$ Chao-Qian Guo ${ }^{1}$ Wen-Jin Yang ${ }^{1} \cdot$ Guo-Qiang Lin $^{2} \cdot$ Bao-Hai Yu'
}

Received: 23 December 2015/Revised: 4 February 2016/Published online: 20 April 2016

(C) The Chinese Society for Metals and Springer-Verlag Berlin Heidelberg 2016

\begin{abstract}
CrN films were deposited on the high-speed-steel substrates by arc ion plating. The effect of an axial magnetic field on the microstructure and mechanical properties was investigated. The chemical composition, microstructure, surface morphology, surface roughness, hardness and film/substrate adhesion of the film were characterized by X-ray photoelectron spectroscopy, X-ray diffraction, scanning electron microscope (SEM), surface morphology analyzer, Vickers microhardness test and scratch test. The results showed that the magnetic field puts much effect on the microstructure, chemical composition, hardness and film/substrate adhesion of the $\mathrm{CrN}$ films. The $\mathrm{N}$ content increases and $\mathrm{Cr}$ content decreases when the magnetic flux density increases from 0 to $30 \mathrm{mT}$. All of the $\mathrm{CrN}$ films were found to be substoichiometric. With an increase in the magnetic flux density, the film structures change in such way: $\mathrm{Cr}_{2} \mathrm{~N} \rightarrow \mathrm{Cr}_{2-}$ $\mathrm{N}+\mathrm{CrN} \rightarrow \mathrm{CrN}+\mathrm{Cr}_{2} \mathrm{~N} \rightarrow \mathrm{CrN}$. The SEM results showed that the number of macroparticles (MPs) on the film surface is significantly reduced when the magnetic flux density increases to $10 \mathrm{mT}$ or higher. The surface roughness decreases with the magnetic field, which is attributed to the fewer MPs and sputtered craters on the film surface. The hardness value increases from $2074 \mathrm{HV}_{0.025}$ at $0 \mathrm{mT}$ (without magnetic field) and reaches a maximum value of $2509 \mathrm{HV}_{0.025}$ at $10 \mathrm{mT}$. The further increase in the magnetic flux density leads to a decrease in the film hardness. The critical load of film/substrate adhesion shows a monotonous increase with the increase in magnetic flux density.
\end{abstract}

KEY WORDS: Magnetic field; Arc ion plating; CrN films; Hardness; Adhesion

\section{Introduction}

Arc ion plating (AIP), also called as vacuum cathodic arc deposition (VAD), has been widely used in cutting tools, molds and mechanical parts, i.e., to improve their

Available online at http://link.springer.com/journal/40195

Yan-Hui Zhao

yhzhao@imr.ac.cn

1 Institute of Metal Research, Chinese Academy of Sciences, Shenyang 110016, China

2 Key Laboratory of Materials Modification by Laser, Ion, and Electron Beams (Dalian University of Technology), Ministry of Education, Dalian University of Technology, Dalian 116024, China mechanical, wear-resistant properties as well as lifetime. Compared with magnetron sputtering (one of the two physical vapor deposition technologies), AIP is characterized as high ionization degree (60\%-90\%), strong film/substrate adhesion, as well as high deposition rate [1, 2]. However, the film quality suffers from severe macroparticles (MPs) contamination. The MPs are ejected with arc plasma during cathodic arc discharge and deposited onto the substrate surface, producing the numerous defects inside the film as well as on its final surface [3,4].

To eliminate the MPs contamination, many methods have been provided, in which magnetic filtering technique has been successfully developed. Among the magnetic field filtering techniques, a curved duct-magnetic filtering (CDMF) technique is popularly used because it can fully eliminate all the MPs contamination on the film surface [5]. 
However, the CD-MF techniques suffer from low deposition efficiency $(1 \%-20 \%)$ [6]. Compared with the CD-MF technique, a straight duct-magnetic filtering (SD-MF) technique is also used to deposit films due to its high deposition efficiency and simple configuration although it cannot eliminate all the MPs contamination. It should be noted that the magnetic flux density usually used in CDMF technique is very low (usually no more than $10 \mathrm{mT}$ ). In this case, only electrons would be magnetized but ions cannot be magnetized so that the ion cyclotron radius became bigger than that of the duct radius [7]. As a result, the ions cannot deposit on the substrate surface and the deposition efficiency was inevitably decreased.

It was showed that under a strong axial magnetic field, the ion energies [8], ion charge states [9] and ion/plasma density [10] were significantly increased compared with those of the conventional arc ion plating due to the plasma interaction with the external magnetic field [8]. Furthermore, the magnetic field has been also used to enhance the synthesis reaction between metal and nonmetal atoms for compound film formation and increase the deposition rate, as well as improve microhardness and adhesion of the deposited films [11].

In our previous work [12], TiN films were deposited by an SD-MF AIP equipment and the results showed that the magnetic flux density can affect the growth texture, surface morphology and mechanical properties. In the present work, $\mathrm{CrN}$ films were deposited by the SD-MF AIP technique to investigate the effect of the magnetic flux density on the microstructure, composition and mechanical properties.

\section{Experimental}

Figure 1 is a schematic view of the SD-MF AIP system used to deposit $\mathrm{CrN}$ film which was illustrated in our previous work [12]. The vacuum chamber had inner diameter of

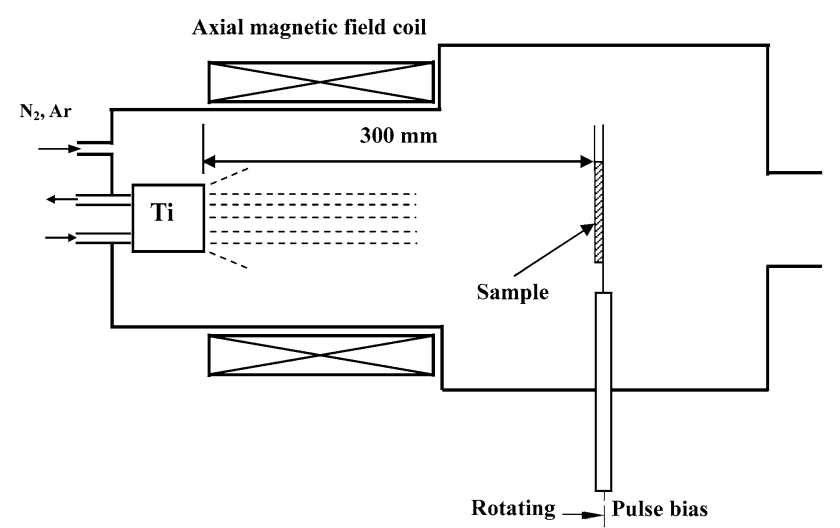

Fig. 1 Schematic view of the axial magnetic field-enhanced arc ion plating system used to deposit $\mathrm{CrN}$ films [12]
$350 \mathrm{~mm}$ and length of $450 \mathrm{~mm}$, and the cathode target (made of metallic $\mathrm{Cr}$ of $4 \mathrm{~N}$ ) was placed at one of the chamber walls. An adjustable electromagnetic coil was located outside the vacuum chamber parallel to the chamber walls. An axial magnetic flux density of up to $100 \mathrm{mT}$ directed parallel to the chamber axis was produced by adjusting the coil current. The value of the magnetic flux density was measured by a magnetometer (SHT-V type from China). The specimens of the size of $20 \mathrm{~mm} \times 12 \mathrm{~mm}$ and $3 \mathrm{~mm}$ in thickness cut from a commercial high-speed-steel (HSS) W6Mo5Cr4V2 (M2) served as the substrates. The substrates were ground, mirror-polished and then were ultrasonically cleaned in alcohol and were dried before placing on the substrate support in the vacuum chamber. The base pressure in the vacuum chamber was $5 \times 10^{-3} \mathrm{~Pa}$. Before film deposition, the $\mathrm{Cr}$ target was used to bombard and to sputter the substrate surface with a constant target arc current of $80 \mathrm{~A}$, Ar gas partial pressure of $0.5 \mathrm{~Pa}$, a dc bias of $-600 \mathrm{~V}$ and bombardment time $5 \mathrm{~min}$. During film deposition, the following parameters were maintained constant: the arc source currents $I_{\mathrm{Cr}}=80 \mathrm{~A}$, the total pressure $2.0 \mathrm{~Pa}$ (Ar partial pressure $P_{\mathrm{Ar}}=0.4 \mathrm{~Pa}, N_{2}$ partial pressure $\left.P_{N_{2}}=1.6 \mathrm{~Pa}\left(P_{N_{2}}: P_{\mathrm{Ar}}=4: 1\right)\right)$, the distance between cathode arc targets and substrates $300 \mathrm{~mm}$ and the total deposition time $40 \mathrm{~min}$. A pulsed bias of approximately $400 \mathrm{~V}$ with duty ratio of $40 \%$ was applied to the substrates, and the pulse frequency was $40 \mathrm{kHz}$. During the deposition, the magnetic flux density on the substrate surface was set as 0 (without magnetic field), 5, 10, 20 and $30 \mathrm{mT}$, respectively. The substrate temperature $T_{\mathrm{s}}$ was in the range of $380-430{ }^{\circ} \mathrm{C}$.

The chemical composition was characterized by X-ray photoelectron spectroscopy (XPS, ESCALAB250), with $\mathrm{Ar}^{+}$of sputtering voltage of $2 \mathrm{kV}$ for $10 \mathrm{~min}$. The microstructure characterization was evaluated by normal X-ray diffraction (XRD, Rigaku, Japan, D/max 2400 with $\mathrm{Cu} K \alpha=0.154056 \mathrm{~nm}$ ). The surface morphology and cross-sectional images of $\mathrm{CrN}$ films were characterized by S-3400N scanning electron microscopy (SEM). The deposition rate was directly measured from the SEM crosssectional images. The surface roughness $(\mathrm{Ra})$ was characterized by a KLA-Tencor Alpha-Step IQ surface profiler. Hardness $(H)$ measurements were taken by using a microhardness tester with a Vickers tip, and the maximum applied load was $25 \mathrm{~g}$. To get rid of the non-uniformity of the films, the calculations were averaged over more than 10 measurements. The film/substrate adhesion data of the scratch tests were obtained by using a multi-functional scratch tester (WS-2005), with a loading speed of $100 \mathrm{~N} /$ min, horizontal velocity of $10 \mathrm{~mm} / \mathrm{min}$ and maximum scratching length of $10 \mathrm{~mm}$. The critical loads were determined from the acoustic signal. 


\section{Results and Discussion}

\subsection{Chemical Composition}

Table 1 shows the chemical composition of the deposited $\mathrm{CrN}$ film. It can be seen that the $\mathrm{N}$ content increases and $\mathrm{Cr}$ content decreases when the magnetic flux density increases from 0 to $30 \mathrm{mT}$. All of the $\mathrm{CrN}$ films were found to be sub-stoichiometric, with the $\mathrm{N} / \mathrm{Cr}$ ratio altering from 0.404 to 0.869 with increasing magnetic flux density. It is basically similar to the results of Wan et al. [13], in which $\mathrm{CrN}$ films were deposited by arc ion plating, and the results showed that at different nitrogen pressures (0.4-2.0 Pa) and different pulse bias voltages $(0$ to $-400 \mathrm{~V})$, all the $\mathrm{CrN}$ films show sub-stoichiometry, with the $\mathrm{N} / \mathrm{Cr}$ ratio in the range of $0.59-0.83$ and $0.67-0.79$, respectively. Also, Qdén et al. [14] showed an average $\mathrm{N} / \mathrm{Cr}$ ratio of 0.85 in the arcdeposited $\mathrm{CrN}$ films.

It was shown that nitrogen could be easily ionized with a strong axial magnetic field enhancement during arc ion plating due to extensive collision between energetic electrons and nitrogen gas [15]. In this case, the higher $\mathrm{N}$ ions density and higher charged state of ions in arc plasma will be obtained due to the higher magnetic flux density [16]. When the magnetic flux density was low $(0-5 \mathrm{mT})$, many particles such as electrons, metal ions, neutral atoms and macroparticles did not react sufficiently with $\mathrm{N}$ ions with low density before depositing on the substrates due to low axial magnetic flux density; thus, the $\mathrm{Cr}$ content was high and the $\mathrm{N}$ content was relatively low in the films. When the magnetic flux density exceeded $10 \mathrm{mT}$, the $\mathrm{N}$ ions with high density would react with the particles and the superfluous $\mathrm{N}$ atoms could squash into the octahedral interstitial position of $\mathrm{CrN}$ structure. Thus, the $\mathrm{N} / \mathrm{Cr}$ ratio can be increased to a saturated value.

\subsection{Film Thickness}

Figure 2 gives the film thickness as a function of magnetic flux density. It can be seen that the film thickness firstly increased and then decreased with the increase in the

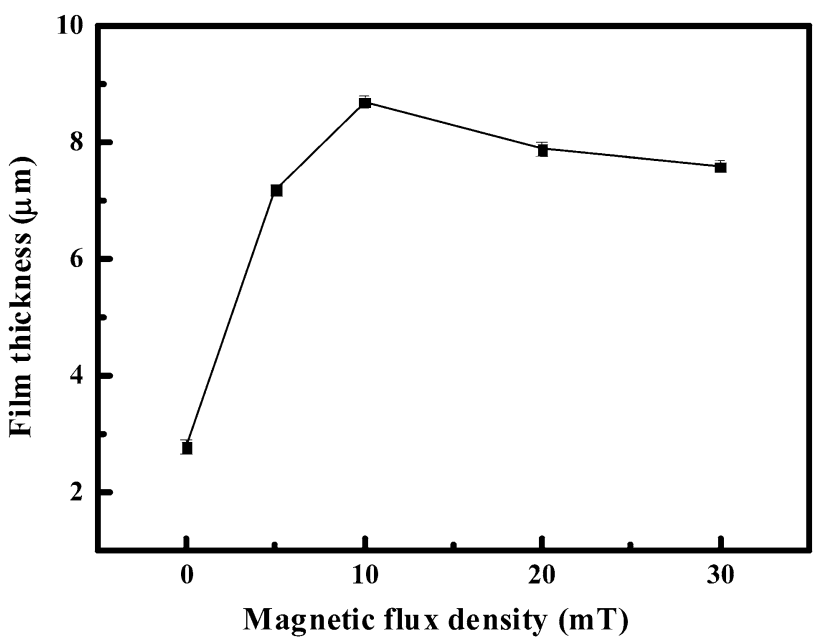

Fig. 2 Film thickness as a function of magnetic flux density

magnetic flux density. The film thickness increases from $2.8 \mu \mathrm{m}$ at $0 \mathrm{mT}$ to $8.7 \mu \mathrm{m}$ at $10 \mathrm{mT}$ and then decreases to $7.6 \mu \mathrm{m}$ at $30 \mathrm{mT}$.

When applying an axial magnetic field to the conventional arc ion plating, ion energies [8], ion charge states [9] and ion/plasma density [10] were significantly increased due to the plasma interaction with the external magnetic field [8]. The higher the magnetic flux density is, the higher the plasma density is. In this case, the high plasma density would greatly increase the film thickness. Above $15 \mathrm{mT}$, the resputtering effect of the film surface from the ion bombardment would play an important role in the final film thickness. The higher the magnetic flux density is, the stronger the resputtering effect is, and therefore a decrease in the film thickness is obtained. In addition, the decrease in the film thickness could be possibly related to the densification of the films caused by the enhanced ions bombardment with the increase in the magnetic flux density [12].

\subsection{Film Structure}

Figure 3 shows the $\mathrm{X}$-ray diffraction patterns of $\mathrm{CrN}$ films at different magnetic flux densities. Without external magnetic field, it shows the diffraction peaks that can be assigned to be

Table 1 Chemical composition of the $\mathrm{CrN}$ film

\begin{tabular}{llll}
\hline Magnetic field intensity $(\mathrm{mT})$ & Cr (at.\%) & N (at.\%) & N/Cr atomic ratio (\%) \\
\hline 0 & $71.2 \pm 0.1$ & $28.8 \pm 0.1$ & 0.404 \\
5 & $69.1 \pm 0.1$ & $30.9 \pm 0.1$ & 0.447 \\
10 & $62.0 \pm 0.1$ & $38.0 \pm 0.1$ & 0.613 \\
20 & $55.2 \pm 0.1$ & $44.8 \pm 0.1$ & 0.812 \\
30 & $53.5 \pm 0.1$ & $46.5 \pm 0.1$ & 0.869 \\
\hline
\end{tabular}




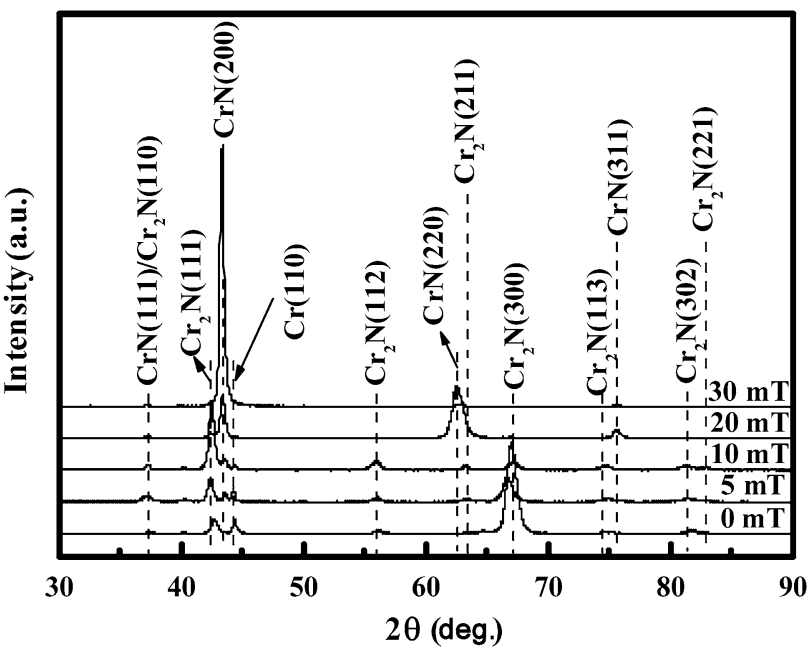

Fig. 3 X-ray diffraction patterns of $\mathrm{CrN}$ films at different magnetic flux densities

hcp $\mathrm{Cr}_{2} \mathrm{~N}$ phase. In this case, the film consists of $\mathrm{Cr}_{2} \mathrm{~N}$ phase. When the magnetic flux density increases further from 5 to $10 \mathrm{mT}$, the diffraction peak intensity of $\mathrm{CrN}$ gradually increases. Compared to the relative diffraction peak intensity, the film is mainly consisted of $\mathrm{Cr}_{2} \mathrm{~N}$ phase with few $\mathrm{CrN}$ phase. When the magnetic flux density increases to higher value (20 mT), the film mainly consists of $\mathrm{CrN}$ phase with very few $\mathrm{Cr}_{2} \mathrm{~N}$ phases and the diffraction peak of $\mathrm{CrN}$ phase in preferential orientation (220) is observed. At the higher magnetic flux density $(30 \mathrm{mT})$, the film basically consists of $\mathrm{CrN}$ phase with only one diffraction peak (200) with very high intensity. Under the condition of external magnetic field, the film structures change in such way: $\mathrm{Cr}_{2} \mathrm{~N}+\mathrm{Cr} \rightarrow \mathrm{Cr}_{2} \mathrm{~N}+\mathrm{Cr}+\mathrm{CrN} \rightarrow \mathrm{CrN}+\mathrm{Cr}_{2} \mathrm{~N} \rightarrow \mathrm{CrN}$. Such changes are obviously influenced by the external magnetic field. The arc ion plating is characterized by the formation of energetic and highly ionized flows of lowtemperature plasma. Moreover, the synthesis reaction between metal and nonmetal atoms would lead to the compound film formation with the increase in the magnetic flux density, which is benefit for $\mathrm{CrN}$ phase formation [11]. In addition, the diffraction lines shift to lower angles detected by the XRD spectra, indicating negative stresses in these films. It can be attributed to stronger ions bombardment caused by increasing magnetic flux density.

The Cr phase existence at low magnetic flux density is attributed to incorporated macroparticles which have previously been reported to have a core consisting of pure metal phase [17]. At low magnetic flux density (0 to $5 \mathrm{mT}$ ), the number of the macroparticles on the film surface is rather large, which makes it possible to form $\mathrm{Cr}$ phase in the core of the macroparticles. On the other hand, the film thickness increases from 2.8 to $7.2 \mu \mathrm{m}$ when the magnetic flux density increases from 0 to $5 \mathrm{mT}$. X-ray may be difficult to penetrate so high thickness of $7.2 \mu \mathrm{m}$. In this case, $\mathrm{Cr}$ phase rather than substrate iron phase is possible to exist at $5 \mathrm{mT}$ although the diffraction lines of iron (M2 substrate) and $\mathrm{Cr}$ are positioned at the same places.

Wan et al. [13] investigated the effects of nitrogen pressure and pulse bias voltage on the $\mathrm{CrN}$ films deposited by the same arc ion plating technique, and the results showed that increasing the nitrogen pressure causes a phase transformation from $\mathrm{CrN}+\mathrm{Cr}_{2} \mathrm{~N}+\mathrm{Cr} \rightarrow \mathrm{CrN}+\mathrm{Cr} \rightarrow \mathrm{CrN}$ and increasing bias voltage leads to $\mathrm{CrN}$ phase formation and minor $\mathrm{Cr}_{2} \mathrm{~N}$ phase formation. But the results of Mo et al. [18] showed that the $\mathrm{CrN}$ phase content of $\mathrm{CrN}$ films increases, while the $\mathrm{Cr}_{2} \mathrm{~N}$ phase content decreases with increasing substrate bias voltage.

When magnetic flux density was low (0 to $5 \mathrm{mT}$ ), the nitrogen pressure was relatively high, but $\mathrm{Cr}_{2} \mathrm{~N}$ phase was more easily formed than $\mathrm{CrN}$ phase. Therefore, the film consists mainly of $\mathrm{Cr}_{2} \mathrm{~N}$ phase and some $\mathrm{Cr}$ phases. When the magnetic flux density was high enough, the reaction between $\mathrm{N}$ ions and $\mathrm{Cr}$ ions was sufficient and no $\mathrm{Cr}_{2} \mathrm{~N}$ and $\mathrm{Cr}$ phases appeared anymore and $\mathrm{CrN}$ phase was formed. It is confirmed by the XPS spectra of $\mathrm{Cr} 2 p 3 / 2$ and $\mathrm{N} 1 s$, as shown in Fig. 4. The $\mathrm{Cr} 2 p 3 / 2$ binding energies for $\mathrm{Cr}$ and $\mathrm{CrN}$ are $574.7 \mathrm{eV} \mathrm{[19]} \mathrm{and} 575.1 \mathrm{eV}$ [20], respectively. However, the $\mathrm{Cr} 2 p 3 / 2$ binding energies for $\mathrm{Cr}_{2} \mathrm{~N}$ are relatively higher, which can be assigned to $577.1 \mathrm{eV}$ [21]. The $\mathrm{N} 1 s$ binding energy for $\mathrm{CrN}$ is $397.6 \mathrm{eV}$ and for $\mathrm{Cr}_{2} \mathrm{~N}$ is $399.2 \mathrm{eV}$ [20]. When magnetic flux density increases from 0 to $30 \mathrm{mT}$, the $\mathrm{N} 1 s$ peaks move to the low binding energy side, while the $\mathrm{Cr} 2 p 3 / 2$ peaks move to the high binding energy. It indicates that increasing magnetic flux density tends to improve the formation of $\mathrm{CrN}$ phase.

The results of Mo et al. [18] showed that $\mathrm{Cr}_{2} \mathrm{~N}$ phase content of the film decreased, while the $\mathrm{CrN}$ phase content increased with increasing substrate bias voltage in the $\mathrm{CrN}$ films deposited by filtered arc ion plating. The similar tendency was also observed by Wan et al. [13]. It seemed that magnetic flux density had the same effect of higher substrate bias voltage due to higher energetic particles in plasma caused by them, and in consequence, the possibility of the structure change would be predicted in the deposited films.

\subsection{Surface Morphology and Roughness}

Figure 5 shows the SEM morphologies of the $\mathrm{CrN}$ films at different magnetic flux densities. Without magnetic field (see Fig. 5a), a lot of macroparticles (MPs) with size in the range of about $0.1-12 \mu \mathrm{m}$ were seen on the surface of the film. At low magnetic flux density ( $5 \mathrm{mT}$, see Fig. $5 \mathrm{~b}$ ), the number of MPs is reduced slightly. But with the further increase in the magnetic flux density (see Fig. 5c, d), the number of MPs is significantly decreased with a few of 

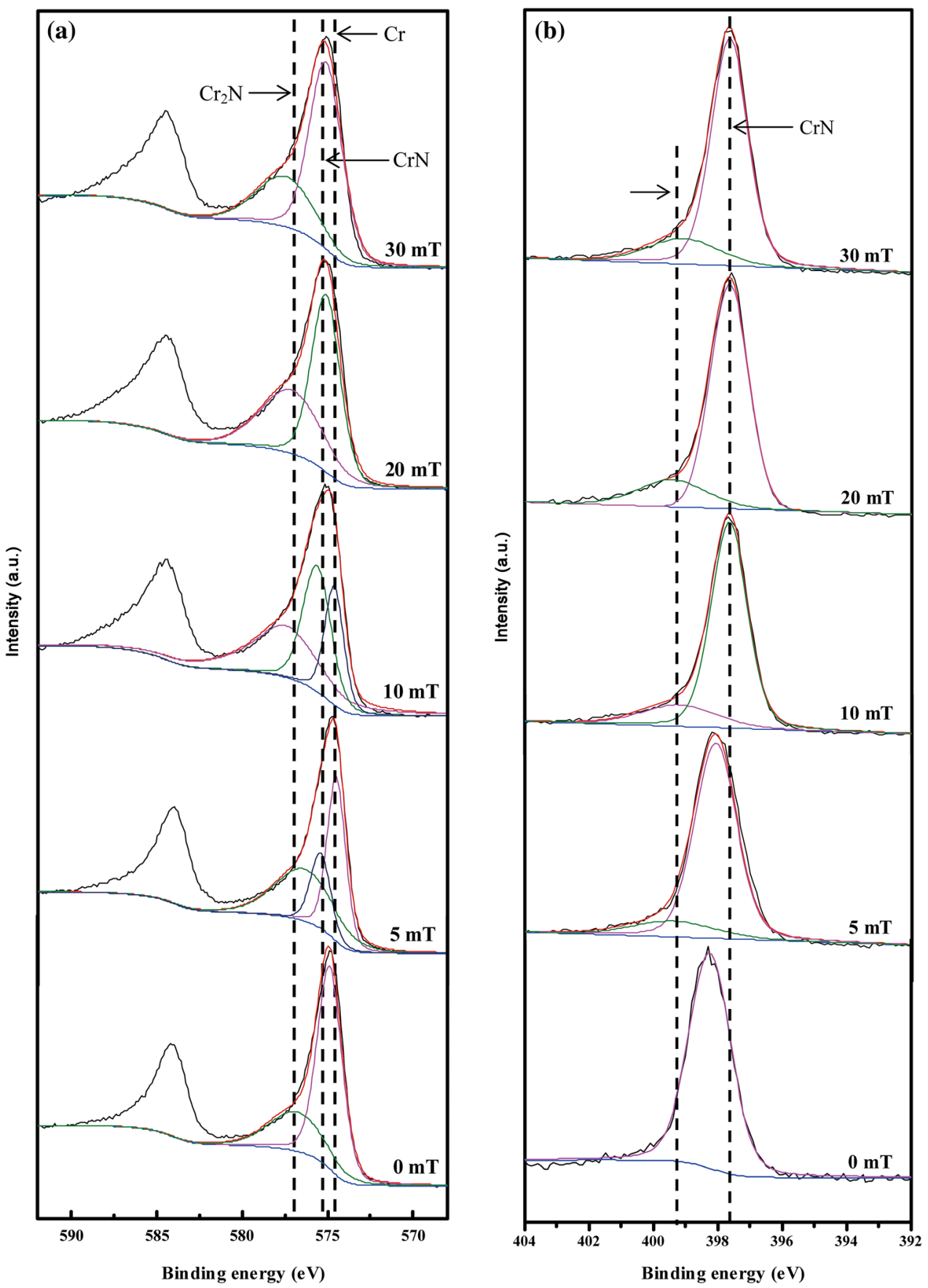

Fig. 4 Binding energy change of XPS results of a $\mathrm{Cr} 2 p 3 / 2$, b N $1 s$ when being deposited at different magnetic flux densities

sputtered craters on the film surface. Moreover, the size of MPs is also decreased, and they are not larger than $5 \mu \mathrm{m}$.

The sputtered craters in Fig. 5 may be related to the strong ion bombardment from the focused arc plasma beam resulted from the high magnetic flux density. When the MPs were sputtered away by the strong ion bombardment, the craters below the MPs were left on the film surface, similar to our previous results [12].
For the MPs on the film surface, they were related to the cathodic spot movement. When no external magnetic field was exerted, the cathode spot moved at random on the cathode surface with a very low rate, and as a result, a large number of MPs would be jetted out to locate onto the film surface. When a magnetic field is applied perpendicular to the cathode surface (also called as axial magnetic field), the transverse component of the axial magnetic field (parallel 

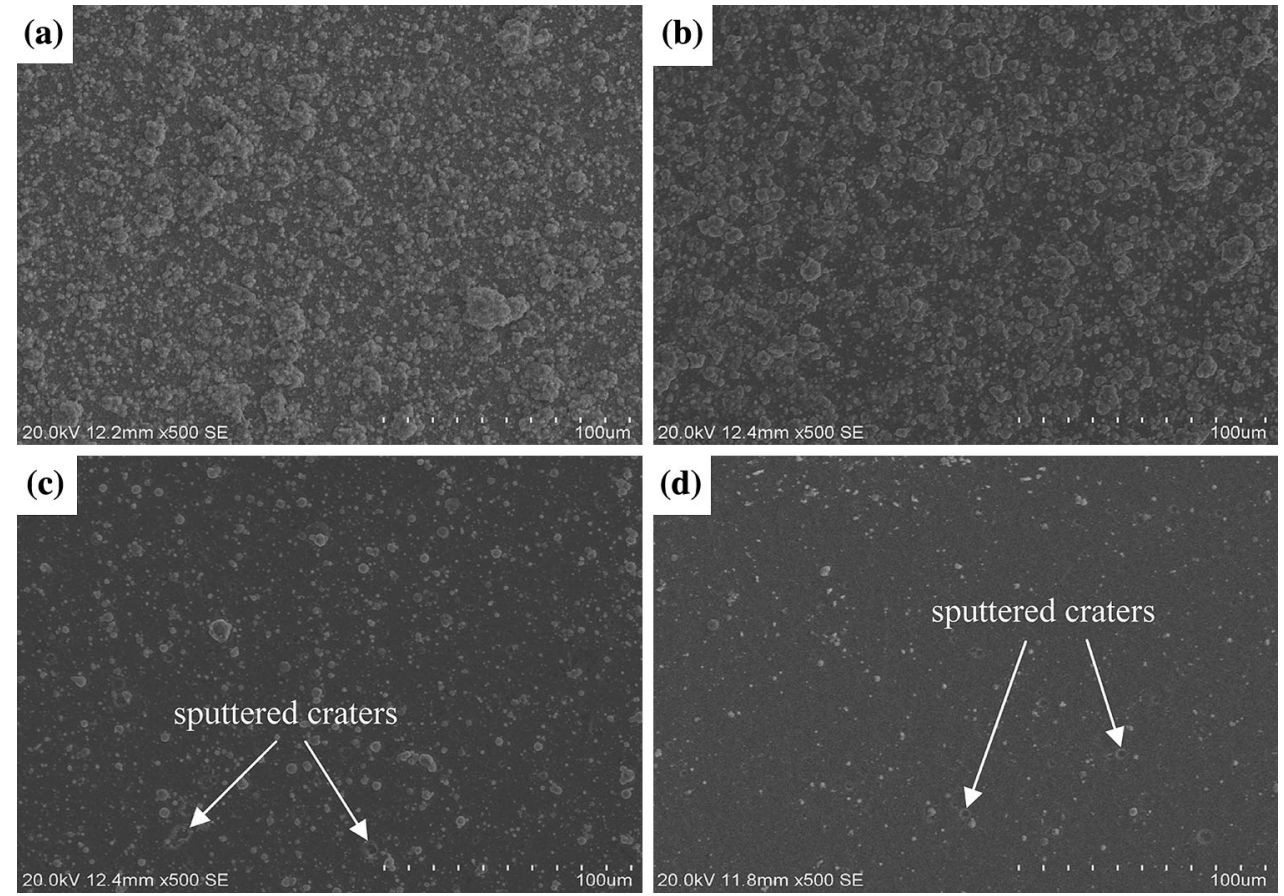

Fig. 5 SEM morphologies of the $\mathrm{CrN}$ films at different magnetic flux densities a $0 \mathrm{mT}$, b $5 \mathrm{mT}$, c $20 \mathrm{mT}$, d $30 \mathrm{mT}$

to the cathode surface) will make the cathode spot move quickly. And the cathode spot velocity is approximately proportional to the magnetic flux density [22]. In this case, only a small number of MPs were injected out to form the MPs pollution due to the quick motion speed of the cathode spot. On the other hand, the axial component of the magnetic field would make the arc plasma focus into a narrow beam with high ion flux [1]. The MPs firstly landing on the film surface would be sputtered out by strong ion bombardment and subsequent MPs impinging with higher kinetic energy obtained from the magnetic field [23]. In this case, the reduced concentration of MPs was observed on the $\mathrm{CrN}$ film surface at higher magnetic flux density.

Figure 6 shows the surface roughness (Ra) of the $\mathrm{CrN}$ films as a function of magnetic flux density. It can be seen that the surface roughness decreases with the increase in the magnetic flux density. It attributes to the fewer MPs and sputtered craters on the film surface (see Fig. 5). It is beneficial to decreasing the coefficient of friction and wear rate. The roughness ( $\mathrm{Ra}$ ) for the present $\mathrm{CrN}$ films ranges from 0.09 to $0.39 \mu \mathrm{m}$, higher than the results of Warcholinski et al. [24] and Wan et al. [13], which can be verified by much more macroparticles on the film surface in the present work than those from the results of Warcholinski et al. [24].

\subsection{Hardness}

Due to large number of the macroparticles, the microhardness value could be easily affected by them. In order to

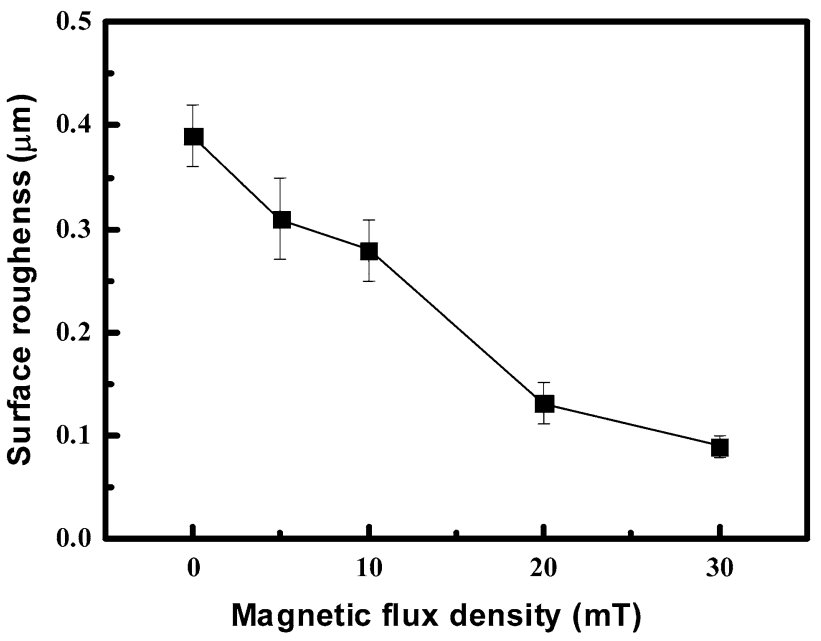

Fig. 6 Surface roughness of $\mathrm{CrN}$ films as a function of magnetic flux density

solve this problem, a method described by Romero et al. [25] can be used. They suggested that the films should be polished with fine diamond powder $(1 \mu \mathrm{m})$. In accordance with this principle, we polished the samples with fine diamond powder $(1 \mu \mathrm{m})$ and the surface roughness of the films has been significantly reduced. Because the roughness (Ra) for the present $\mathrm{CrN}$ films ranged from 0.09 to $0.39 \mu \mathrm{m}$, the indentation depth was not $<20 \times \mathrm{Ra}$ (arithmetic mean roughness). On the other hand, due to the high film thickness (from 2.8 to $8.7 \mu \mathrm{m}$ ), the indentation depth was not $>1 / 10$ of total thickness of the films. In this case, 


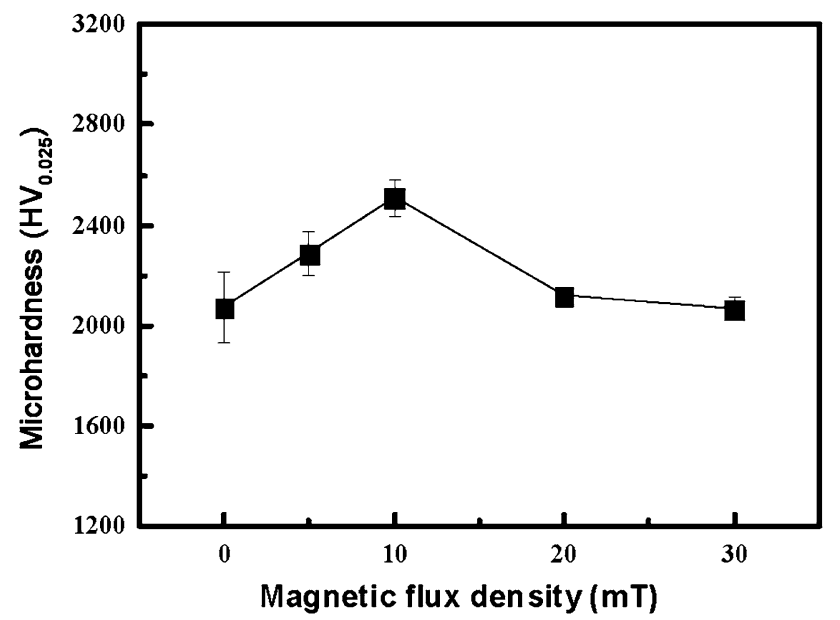

Fig. 7 Microhardness of $\mathrm{CrN}$ films as a function of magnetic flux density

all the data obtained in the present work were not affected by film thickness and surface roughness. Then, the repeated microhardness test was carried out and the newly obtained data as a function of magnetic flux density are shown in Fig. 7. It can be seen that the hardness value increases from $2074 \mathrm{HV}_{0.025}$ at $0 \mathrm{mT}$ (without magnetic field) and reaches a maximum value of $2509 \mathrm{HV}_{0.025}$ at $10 \mathrm{mT}$. The further increase in the magnetic flux density leads to a decrease in the film hardness.

Hexagonal phase $\mathrm{Cr}_{2} \mathrm{~N}$ shows a higher hardness than the cubic phase $\mathrm{CrN}$ [17]. For the film deposited at magnetic flux density of $10 \mathrm{mT}$, the higher hardness is because the film consists mainly of $\mathrm{Cr}_{2} \mathrm{~N}$ phase. For higher magnetic flux density, only softer cubic $\mathrm{CrN}$ phase exists, which will be responsible for the hardness decrease. It is similar to the results of Rebholz et al. [17].

Compared with the film without magnetic field, at low magnetic flux density $(10 \mathrm{mT})$, the high hardness may be related to film densification caused by strong ion bombardment from application of the external axial magnetic field. On the other hand, the significantly reduced MPs on the film surface would be beneficial to the hardness enhancement. But with the further increase of the magnetic flux density, the energy and flux of $\mathrm{Cr}$ ions was increased, and as a result, more $\mathrm{Cr}$ ions would bomb the growing film surface. At higher bombardment energies, a layer with more radiation damages probably formed due to high-energy ion bombardment [26].

\subsection{Critical Load of Film/Substrate Adhesion}

For hard thin films widely used in cutting tools and other mechanical parts, film/substrate adhesion is a very important property for its real service. This property of films will usually be evaluated by scratch method. Figure 8 shows the

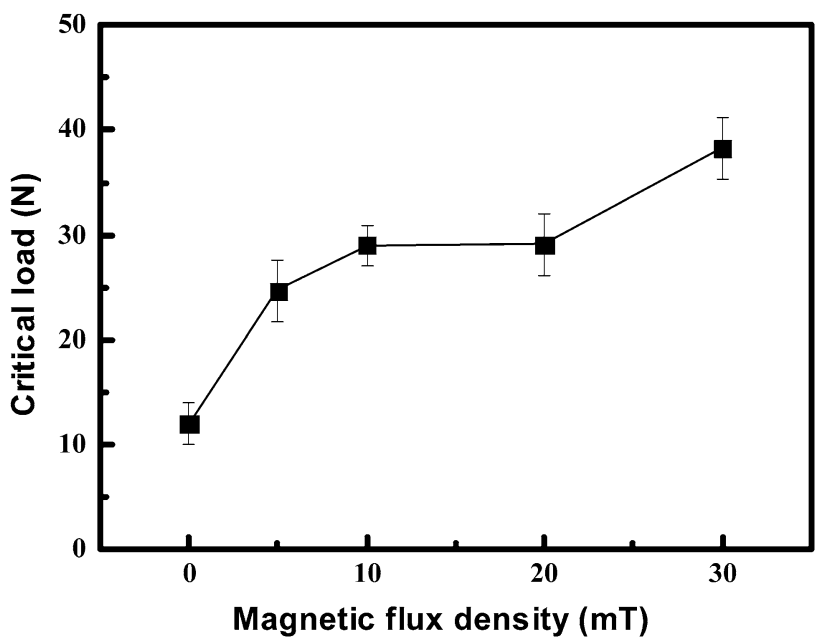

Fig. 8 Critical load of $\mathrm{CrN}$ films as a function of magnetic flux density

critical load curve as a function of magnetic flux density. From this figure, we can see that the critical load significantly increases with the increase in the magnetic flux density. Without the magnetic field, only $12 \mathrm{~N}$ is obtained for the critical load. But when a low magnetic flux density $(5 \mathrm{mT})$ is used, the value of the critical load increases rapidly to $25 \mathrm{~N}$, while at the magnetic flux density of $30 \mathrm{mT}$, the maximum value $39 \mathrm{~N}$ is obtained. This adhesion enhancement would be related to film densification. When an external axial magnetic field is applied, the arc plasma will be easily focused with enhanced plasma energies and density. In this case, the film will be compacted by ion bombardment from the focused plasma. The large number of the MPs on the film surface without the magnetic field would be disadvantageous for film densification. But with the increase in the magnetic flux density, the number of the MPs on the film surface would be obviously reduced, which is beneficial to film densification enhancement.

\section{Conclusion}

CrN films were deposited on high-speed-steel (HSS) substrates by arc ion plating. The axial magnetic field has much effect on the chemical composition, microstructure, surface morphology, hardness and film/substrate adhesion of the $\mathrm{CrN}$ films deposited by arc ion plating. The $\mathrm{N}$ content increases and $\mathrm{Cr}$ content decreases when the magnetic flux density increases from 0 to $30 \mathrm{mT}$. All of the $\mathrm{CrN}$ films were found to be sub-stoichiometric. Higher magnetic flux density would be beneficial to the $\mathrm{CrN}$ phase formation. The SEM results showed that the number of macroparticles (MPs) on the film surface is significantly 
reduced when the magnetic flux density increases to $10 \mathrm{mT}$ or higher. The hardness value varied from $2074 \mathrm{HV}_{0.025}$ to $2509 \mathrm{HV}_{0.025}$. The maximum value was obtained at magnetic flux density of $10 \mathrm{mT}$. The critical load of film/substrate adhesion shows a monotonous increase with the increase in the magnetic flux density.

Acknowledgments The research work was supported by Key Laboratory of Materials Modification by Laser, Ion, and Electron Beams (Dalian University of Technology), Ministry of Education (Grant No. LABKF1405).

\section{References}

[1] P. Sathrum, B.F. Coll, Surf. Coat. Technol. 50, 103 (1992)

[2] Y.H. Zhao, G.Q. Lin, C. Dong, L.S. Wen, J. Mater. Sci. Technol. 21, 423 (2005)

[3] Y.H. Zhao, X.Q. Wang, J.Q. Xiao, B.H. Yu, F.Q. Li, Appl. Surf. Sci. 258, 370 (2011)

[4] Y.H. Zhao, G.Q. Lin, J.Q. Xiao, W.C. Lang, C. Dong, J. Gong, C. Sun, Appl. Surf. Sci. 257, 5694 (2011)

[5] M.B. Taylor, J.G. Partridge, D.G. McCulloch, M.M.M. Bilek, D.R. McKenzie, Thin Solid Films 519, 3573 (2011)

[6] M.M.M. Bilek, Y. Yin, D.R. McKenzie, W.I. Milne, Proceedings of the XVIIth International Symposium on Discharges and Electrical Insulation in Vacuum, Berkeley (1996)

[7] M.M.M. Bilek, D.R. McKenzie, Y. Yin, M.U. Chhowalla, W.I. Milne, IEEE Trans. Plasma Sci. 24, 1291 (1996)

[8] A. Anders, G.Y. Yushkov, J. Appl. Phys. 91, 4824 (2002)
[9] E.M. Oks, I.G. Brown, M.R. Dickinson, R.A. MacGill, H. Emig, P. Spaedtke, B.H. Wolf, Appl. Phys. Lett. 67, 200 (1995)

[10] E.M. Oks, K.P. Savkin, S.Yu. Yushkov, A.G. Nikolaev, A. Anders, I.G. Brown, Rev. Sci. Instrum. 77, 03 B504 (2006)

[11] D.M. Sanders, J. Vac. Sci. Technol. A7, 1181 (1989)

[12] Y.H. Zhao, W.J. Yang, C.Q. Guo, Y.Q. Chen, B.H. Yu, J.Q. Xiao, Acta Metall. Sin. (Engl. Lett.) 28, 984 (2015)

[13] X.S. Wan, S.S. Zhao, Y. Yang, J. Gong, C. Sun, Surf. Coat. Technol. 204, 1800 (2010)

[14] M. Odén, J. Almer, G. Håkansson, M. Olsson, Thin Solid Films 377-378, 407 (2000)

[15] J.M. Schneider, A. Anders, G.Y. Yushkov, Appl. Phys. Lett. 78, 150 (2001)

[16] A. Anders, G. Yushkow, E. Oks, A. Nikolaev, I. Brown, Rev. Sci. Instrum. 69, 1332 (1998)

[17] C. Rebholz, H. Ziegele, A. Leyland, A. Matthews, Surf. Coat. Technol. 115, 222 (1999)

[18] J.L. Mo, M.H. Zhu, Appl. Surf. Sci. 255, 7627 (2009)

[19] C.D. Wagner, W.M. Riggs, L.E. Davis, J.F. Moulder, G.E. Muilenberg, Handbook of X-ray Photoelectron Spectroscopy (Perkin Elmer Corporation, Waltham, 1979)

[20] M. Romand, M. Roubin, Analysis 4, 309 (1976)

[21] NIST data base. http://srdata.nist.gov/xps/

[22] D.Y. Fang, IEEE Trans. Plasma Sci. 11, $110(1983)$

[23] J.S. Yoon, J.G. Han, Surf. Coat. Technol. 94-95, 201 (1997)

[24] B. Warcholinski, A. Gilewicz, J. Ratajski, Z. Kuklinski, J. Rochowicz, Vacuum 86, 1235 (2012)

[25] J. Romero, M.A. Gómez, J. Esteve, F. Montalà, L. Carreras, M. Grifol, A. Lousa, Thin Solid Films 515, 113 (2006)

[26] M. Matsuoka, S. Isotani, W. Sucasaire, N. Kuratani, K. Ogata, Surf. Coat. Technol. 202, 3129 (2008) 